\title{
Efecto de contraste sucesivo negativo en la valoración emocional de imágenes
}

\author{
Lucas Cuenya ${ }^{1,2}$, Giselle Kamenetzky ${ }^{1,2,3}$, Sandro Fosacheca ${ }^{1,2}$ y Alba E. Mustaca ${ }^{1,3^{*}}$ \\ 1 Laboratorio de Psicología Experimental y Aplicada (PSEA). Instituto de Investigaciones Médicas (CONICET) \\ 2 Facultad de Psicologia, Universidad de Buenos Aires \\ 3 Centro del Altos Estudios en Ciencias Humanas y de la Salud (CAECIHS), Universidad Abierta Interamericana (UAI)
}

\begin{abstract}
Resumen: Se presentan dos experimentos para estudiar el efecto de la reducción del valor de incentivo sobre las respuestas de tiempo de observación y valoración de la emocionalidad de las imágenes, mediante una escala Likert. En ambos estudios un grupo de sujetos observó una serie de fotografías del Sistema Internacional de Imagen Afectiva (International Affective Picture System; IAPS) clasificadas como placenteras de alta activación (fase de pre-cambio) y luego, placenteras de baja activación (fase de post-cambio, Grupo Experimental, GE). Otro grupo observó en ambas fases solamente las imágenes placenteras de baja activación (Grupo Control, GC). No hubo efectos en el tiempo de observación de las imágenes pero sí en su valoración emocional. Durante la fase de post-cambio el GE evaluó las imágenes de baja activación como menos emocionales que el GC. El Experimento 2 replica el resultado cuando se interpone una tarea distractora entre cada ensayo de presentación de las imágenes. Estos resultados indican que la valoración afectiva de las imágenes está modulada por efectos de contraste negativo y que su mecanismo es de origen central.
\end{abstract}

Palabras clave: Contraste negativo; imagen; IAPS; emoción.

\section{Introducción}

Está ampliamente documentado que los estímulos visuales no sólo pueden adquirir propiedades motivacionales y valor de incentivo por asociaciones previas con otros estímulos más potentes, sino que también pueden actuar como efectivos reforzadores desde etapas muy tempranas del desarrollo reforzando otras conductas. Por ejemplo Kraebel, Fable y Gerhardstein (2004) entrenaron a un grupo de bebés de entre 2 a 3 meses de edad en una prueba en la que el pataleo era contingente con el movimiento de un móvil que el niño observaba. Hallaron que la tasa de la respuesta se incrementaba significativamente en contraposición con un grupo no contingente, en que el pataleo no producía el movimiento del móvil. Al mismo tiempo determinaron que el efecto se encontraba aun cuando la estimulación visual no se acompañaba de ninguna estimulación auditiva.

Estas propiedades de los estímulos visuales se extiende a otros menos tangibles, manipulables y más simbólicos, como son las imágenes, fotografías o películas. En la vida cotidiana nos encontramos expuestos continuamente a imágenes provenientes de nuestro entorno, ya sea desde la televisión, el cine, internet o la publicidad, y las mismas muy a menudo influyen sobre nuestras conductas, pensamientos, emociones, toma de decisiones, etc. Las imágenes que observamos portan habitualmente con una historia de condicionamiento que las convierte en potentes estímulos condicionados. Se ha informado, por ejemplo, que los sujetos adictos a la cocaína eligen con más frecuencia observar imágenes relacionadas al consumo de la droga y que la frecuencia de su elección es

* Dirección para correspondencia [Correspondence address]:

A. Mustaca. Av. Combatientes de Malvinas 3150 (1426), Buenos Aires (Argentina). E-mail: albamustaca@gmail.com
Title: Successive negative contrast effect on the emotional evaluation of images

Abstract: Two experiments were presented in which the International Affective Picture System (IAPS) was used to study the effect of the incentive value downshift upon the observation time and emotional valuation responses in humans. One group observed pleasant slides of high arousal (pre-shift phase) and then pleasant slides of low arousal (post-shift phase, Experimental Group, GE). The Control Group (GC) observed pleasant slides of low arousal in both phases. There was not an effect on the observation time measure, but a successive negative contrast (SNC) effect was found in the emotional valuation measure. During the post-shift phase, the GE evaluated the slides as less emotional than the GC. These results indicate that the affective evaluation of the images is modulated by negative contrast effect.

Key words: Negative contrast; images; IAPS; emotion. equiparable a la de imágenes agradables, mientras que los sujetos no adictos eligen verlas con la misma frecuencia que las figuras desagradables (Moeller et al., 2009).

Un instrumento típico para estudiar las relaciones entre imágenes, atención, emoción y memoria es una serie de fotografías estandarizadas por investigadores del NIMH Center for Emotion and Attention (CSEA) de la Universidad de Flori$\mathrm{da}$, que se elaboraron con el objetivo de proporcionar materiales válidos para estudiar la emoción y la atención (International Affective Picture System, IAPS, Lang, Bradley y Cuthbert, 1999). El instrumento se compone de un conjunto de fotografías en color capaces de evocar emociones y cuyos contenidos tienen un muestreo de un gran abanico de categorías semánticas. Cada imagen del IAPS posee un valor normalizado en las dimensiones bipolares de valencia afectiva, con un rango que va desde lo muy agradable a muy desagradable, y de activación (arousal en inglés), cuyo rango oscila entre la alta activación a la baja activación. Las imágenes del IAPS son capaces de producir cambios psicofisiológicos y conductuales en los sistemas autonómico, muscular facial y esquelético reflejo (e.g., Cuthbert, Bradley y Lang, 1996; Patrick, Bradley y Lang, 1993; Patrick y Lavoro, 1997). Las investigaciones hallaron una activación específica de la amígdala, una estructura implicada en las respuestas emocionales, ante la presentación tanto de imágenes con contenido placentero (e.g., encuentros sexuales) como desagradable (e.g., mutilaciones), actividad no registrada cuando se presentaban imágenes neutras (ver Lang y Bradley, 2010). Los estudios con resonancia magnética funcional mostraron que el núcleo caudado es otra de las estructuras cuya actividad es activada por la presentación de imágenes con contenido emocional. Esta estructura posee una respuesta sensible al contenido emocional de las imágenes, puesto que las que poseen con- 
tenido desagradable la activaron con mayor intensidad que aquellas con contenido placentero (Carretié et al., 2009).

También se encontró que las filminas del IAPS tienen propiedades semejantes a estímulos incondicionados apetitivos y aversivos y por lo tanto valores motivacionales y de incentivo. Por ejemplo, Marcos y Redondo (2004) hallaron que la respuesta de parpadeo provocada por un ruido fuerte era más intensa cuando se presentaba en presencia de un estímulo condicionado apareado previamente a imágenes del IAPS muy desagradables y muy activantes. Con el IAPS también se halló que las respuestas ante las imágenes están reguladas por experiencias previas, sean por procesos puramente atencionales como de aprendizaje. Por ejemplo, Neumann y Lozo (2012) mostraron que las emociones que provocan las figuras del IAPS están influenciadas por procesos de priming. También se halló que la valoración de fotografías está regulada por la habituación (Bradley, Lang y Cuthbert, 1993), por su apareamiento previo con estímulos aversivos o hedónicos (Hamm, Greenwald, Bradley y Lang, 1993) y por la presentación repetida de imágenes aversivas (Smith, Bradley y Lang, 2005).

Poco se ha estudiado sobre el valor emocional que las personas pueden darle a las fotografías en función de lo que esperan ver. En nuestra continua exposición a imágenes en la vida cotidiana, es posible que formemos expectativas a través de procesos de memoria acerca de las que esperamos observar en determinados contextos, y cuando las mismas no son las esperadas, probablemente podemos sorprendernos, decepcionarnos o incluso sentirnos eufóricos, al igual que ocurre con otro tipo de incentivos. La psicología ha desarrollado procedimientos para evaluar las respuestas de los sujetos ante los cambios inesperados del refuerzo, con el marco teórico de la teoría de la frustración de Amsel (1992) y la de Gray y McNaughton (2000), entre otros. Uno de los métodos utilizados es el Contraste Sucesivo Negativo (CSN). Consiste en la reducción abrupta de la respuesta instrumental o consumatoria ante la presencia de un reforzador de baja magnitud en un grupo entrenado previamente con un reforzador de mayor magnitud, en comparación con la respuesta de un grupo control que siempre obtuvo el refuerzo de baja calidad (e.g., Cuenya, Fosacheca, Mustaca y Kamenetzky, 2011; Flaherty, 1996;). El CSN se estudió intensamente con modelos animales no humanos, tales como ratas (e.g., Cuenya et al., 2011; Cuenya, et al., 2012), ratones (Mustaca, Bentosela y Papini, 2000), perros (e.g., Bentosela, Jakovcevic, Elgier, Mustaca y Papini, 2009) y aves (e.g., Freidin, Cuello y Kacelnik, 2009). Estos estudios mostraron que en el CSN están involucradas reacciones emocionales, cognitivas y comportamentales relacionadas con la ansiedad, el estrés y el dolor (Amsel, 1992; Flaherty, Becker y Pohorecky, 1985; Flaherty, Blitzer y Collier, 1978; Papini, Wood, Daniel y Norris, 2006; Pellegrini y Mustaca, 2000).

Los estudios sobre cambios inesperados del refuerzo en humanos tienen en común la utilización de protocolos que implican alteraciones en la presentación de reforzadores apetitivos, sean éstos sociales, alimentos, juegos, etc. (ver Ka- menetzky et al., 2009). Encontramos un solo antecedente relacionado con los efectos de contraste en la valoración de imágenes. Mischel y Masters (1966) estudiaron, en un grupo de niños, el efecto de contraste sobre la valoración de un documental audiovisual que fue interrumpido de manera inesperada. A tres grupos se les proporcionaba diferente información: a) que el problema no tenía solución, b) que era probable que la tuviera o c) que se podía arreglar. Para un cuarto grupo (control), el video no se interrumpía. Luego se les informaba que la falla se había solucionado y se completaba la proyección. Cuando se pidió a los niños que evaluaran la película, el grupo que había sido informado sobre la imposibilidad de continuar viendo el documental hizo una evaluación más favorable que el resto de los grupos. Este experimento mostró que las respuestas de los niños variaron en función de las posibilidades o expectativas de acceso al reforzador. Este estudio podría sugerir un efecto de contraste positivo, ya que la información sobre la imposibilidad de ver el final del documental provocó una valoración más alta del mismo cuando se lo pudo ver. Sin embargo esta investigación fue realizada en niños y con una película que no solamente contenía imágenes, sino también sonidos, movimientos y contenido verbal, por lo cual el efecto de contraste no puede ser atribuido solamente a las imágenes per se sino a un conjunto estimular más complejo.

El objetivo de los experimentos que presentaremos fue evaluar el efecto del contraste negativo en adultos utilizando imágenes seleccionadas del IAPS. Debido a que los fenómenos de CSN se constatan ante la presentación de un reforzador apetitivo de baja magnitud en presencia de una expectativa o experiencia con un reforzador de mayor calidad, todas las filminas seleccionadas poseían una valencia positiva (emocionalmente placenteras), manipulando su nivel de activación para distinguir aquellas que funcionarían como incentivos de alta magnitud (i.e., valencia positiva - muy activantes), de las que funcionarían como reforzadores de baja magnitud (i.e., valencia positiva - poco activantes). A un grupo de sujetos (grupo experimental, GE), en la fase de pre-cambio se le presentó filminas muy activantes (e.g., pareja besándose), y en la fase de post-cambio, imágenes poco activantes (e.g., un paisaje). Sus respuestas ante el cambio de refuerzo se compararon con las de sujetos a los que siempre se les mostraron imágenes de baja activación (grupo control, GC). El Experimento 1 tuvo como objetivo adicional evaluar la metodología empleada y si la elección de las filminas fue la adecuada. En el Experimento 2 se modificaron algunos parámetros para mejorar la expresión del CSN que se detallarán al comienzo del experimento. En ambos estudios se tomaron como medidas dependientes el tiempo que los sujetos permanecían mirando cada filmina y cómo la valoraban desde el punto de vista emocional. Los sujetos miran más tiempo las fotos placenteras y desagradables que tienen el mismo nivel de activación en comparación con las neutras de baja activación (Sánchez-Navarro, Martínez-Selva, Román y Torrente, 2006), pero no se hallaron datos previos sobre el tiempo de observación de imágenes de valencia po- 
sitiva relacionadas con su nivel de activación. Los resultados del presente trabajo agregarán información acerca de la influencia de los niveles de activación en el tiempo de observación de imágenes de valencia positiva, y además se estudiará si esta medida varía en función de los efectos de contraste. Si el nivel de activación influye en la observación de las figuras y también en su valoración emocional, se predice que durante la fase de pre-cambio los sujetos del GE mirarán las imágenes más tiempo y las valorarán como más emocionales respecto del GC. En cambio, durante la fase de post-cambio, los sujetos del GE disminuirán el tiempo de observación y la valoración de la emocionalidad de las mismas, en comparación con el GC por un efecto de CSN.

\section{Experimento 1}

\section{Método}

Participantes

Participaron 43 sujetos (18 hombres y 25 mujeres) de entre 19 y 44 años de edad. Todos recibían un consentimiento informado para participar voluntariamente del estudio. En el mismo se les aclaraba que el propósito de la investigación se relacionaba con las reacciones psicológicas de las personas ante la presentación de distintas imágenes, asegurándoles un trato completamente confidencial de los resultados. Todos aceptaron participar voluntariamente del estudio y que los resultados puedan publicarse. El protocolo cumple con el Código de Ética de la Asociación de Psicólogos de Buenos Aires (ver www.proyectoetica.org/.../normativas.../Código\%20APBA).

\section{Instrumentos}

Los programas de computadora utilizados fueron los módulos E-Studio y E-DataAid del software E-Prime v1.1 bajo un entorno Windows XP. Para la presentación de las imágenes se utilizó una computadora PC Intel Core2 Duo CPU E4600 2.4GHz. El tamaño de las imágenes en la pantalla de la computadora fue el máximo que puede reproducir un monitor de 17 pulgadas. Se utilizaron las filminas del sistema IAPS de valencia positiva muy activantes y poco activantes. El uso de las filminas no requiere permiso alguno. La selección de las mismas se realizó en función del baremo para hombres y mujeres. En el Apéndice 1 se presenta la nómina de las filminas usadas en cada experimento de acuerdo a la clasificación del sistema IAPS.

\section{Procedimiento}

Luego de dar su consentimiento para participar en la investigación, los participantes pasaban a un cuarto experimental. El mismo se encontraba aislado y a oscuras, por lo que cuando el experimentador dejaba la habitación, los suje- tos realizaban la tarea sin ninguna ventana ni acceso al exterior. Se los invitaba a sentarse frente a una computadora y se les tomaba los datos de edad, sexo y ocupación.

El procedimiento consistía en tres etapas:

1) Familiarización. Luego de pedirles que apagaran cualquier tipo de aparato que pudiese interrumpir la prueba (e.g., teléfonos móviles), se les leía la consigna que aparecía en la pantalla del ordenador: "A continuación se presentarán una serie de imágenes, obsérvela todo el tiempo que desee y pulse la barra espaciadora para cambiar de figura. Luego de la presentación de cada imagen, deberá indicar cuán emocionante le pareció, valorándola de 1 a 5 , siendo 5 , totalmente emocionante, 4 , bastante emocionante, 3 , medianamente emocionante, 2 , poco emocionante y 1 , nada emocionante. Después de dar su valoración se presentará la otra imagen y deberá realizar lo mismo. Presione cualquier tecla para comenzar". Después aparecía una filmina de alta activación que debía observar todo el tiempo que deseara, luego debía presionar una tecla y aparecía en la pantalla una escala Likert de 5 puntos donde debía presionar otra tecla para que informara cuán emocionante le pareció la imagen. Luego de dos segundos en los que observaban una cruz central blanca sobre un fondo de pantalla oscuro, se presentaba la otra imagen y debía realizar la misma tarea. Este ciclo se repetía tres veces, al cabo del cual el experimentador se retiraba del cuarto para dar comienzo a la etapa siguiente.

2) Fase de Pre-cambio. Fue igual a la fase previa, excepto que a los sujetos del GE $(n=21)$ se les presentaban una serie de diez filminas de alta activación, y al GC $(n=22)$, imágenes de baja activación en un orden secuencial, es decir que para todos los sujetos de cada grupo la secuencia fue la misma.

3) Fase de Post-cambio. Comenzaba luego de la imagen número 10 en la cual ambos grupos recibieron otras 10 filminas de baja activación.

Se tomaron dos variables dependientes: 1) tiempo de observación de la filmina (en milisegundos), que se consideraba desde que se presentaba la imagen hasta que el sujeto presionaba una tecla (el participante no sabía que se registraba esa medida); 2) valoración de la filmina con la escala Likert, de acuerdo a lo descripto anteriormente.

Las respuestas quedaban registradas mediante el software EStudio para que luego se visualicen con el software EDataAid. El análisis estadístico se realizó con el programa Statistica y se utilizó un ANOVA mixto. El nivel de significación se estableció para todos los análisis en $\alpha=.05$. 

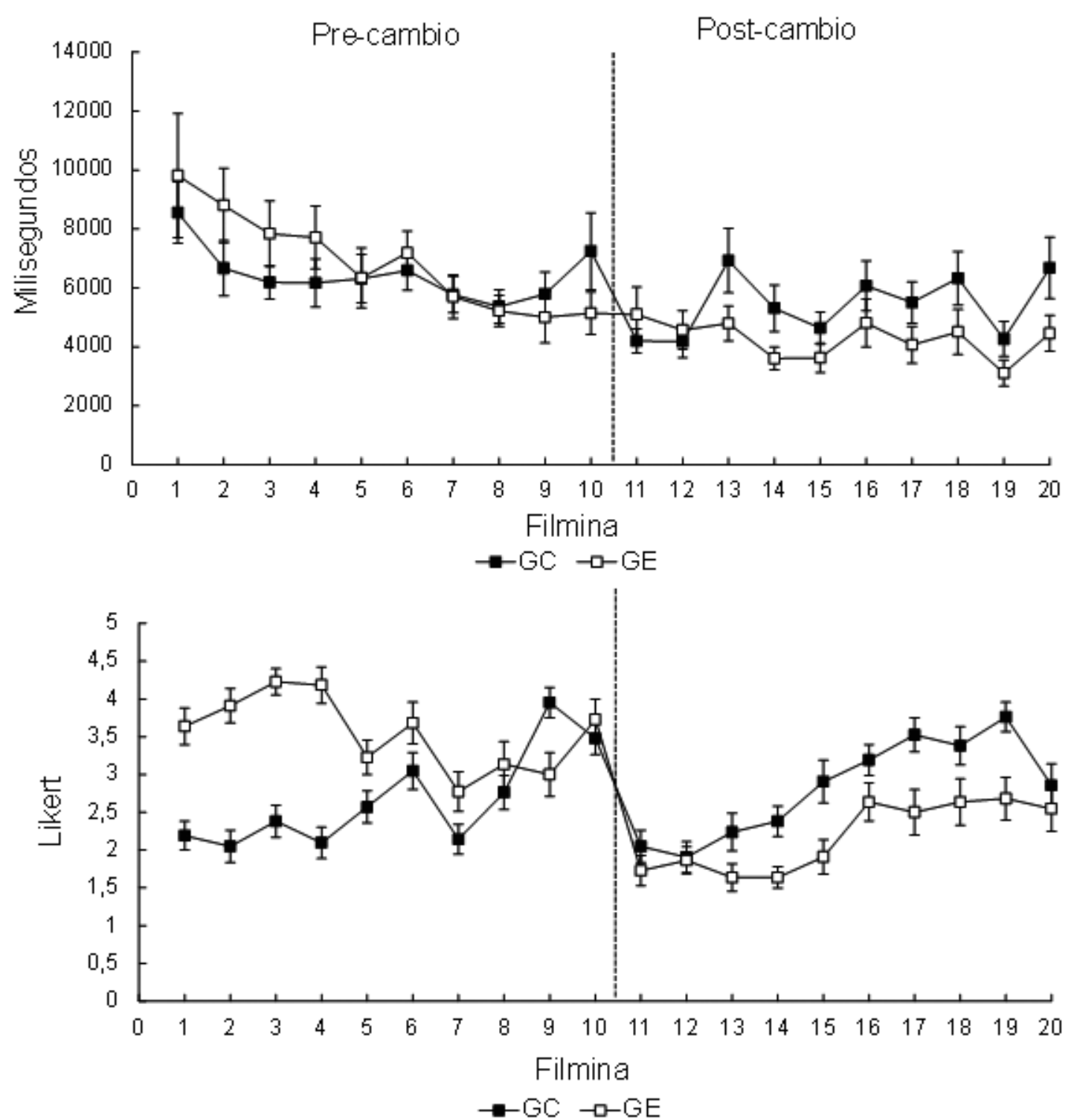

Figura 1. Experimento 1. Panel superior: Promedio ( $\pm E T M$ ) del tiempo de observación de las fotos del IAPS (en milisegundos) en función del orden de presentación y de los grupos. Panel inferior: Promedio ( \pm ETM) de la puntuación en la escala Likert de evaluación emocional de las fotos del IAPS en función de los grupos. GE: Grupo experimental; GC: Grupo control.

\section{Resultados y discusión}

Como no se hallaron diferencias significativas entre hombres y mujeres $(p>$.05), los resultados se analizaron en forma conjunta.

Tiempo de observación. La Figura 1 (panel superior) muestra el promedio del tiempo de observación en función de cada imagen y de los grupos. Se observa que en la fase de precambio ambos grupos tienden a disminuir gradualmente el tiempo de observación con el trascurso del experimento. En la fase de post-cambio sigue la misma tendencia aunque en algunas filminas los sujetos del GE tienen a disminuir aun más el tiempo de observación respecto del GC y de la fase de pre-cambio. Los resultados estadísticos realizados con una ANOVA mixto de un factor de medidas independientes (GE vs. GC) y un factor de medidas repetidas (filminas) arrojan diferencias significativas solamente en el factor filminas, tanto en la fase de pre-cambio, $F(9,369)=4.83, p<$ .000001 , como en la de post-cambio, $F(9,369)=3.19, p<$ .0009 . Este resultado indica que ambos grupos disminuyeron gradualmente el tiempo de observación en función de la presentación de las fotos.

Escala Likert. La Figura 1(panel inferior) muestra el promedio de la valoración de las filminas en función de las fases de pre-cambio y post-cambio. Se observa que la valoración 
que realizan los sujetos del GE en la fase de pre-cambio es mayor que las del GC, aunque tienden a igualarse a partir de la figura 6. Durante la fase de post-cambio los sujetos del GE valoran las filminas como menos emocionales respecto del GC. Un ANOVA mixto muestra resultados que confirman estas observaciones. La fase de pre-cambio arroja diferencias significativas en todos los factores: Grupo, $F(1,41)$ $=24.90, p<.0001$; Filminas, $F(9,369)=5.23, p<.0001, \mathrm{y}$ la interacción de Grupo x Filminas, $F(9,369)=9.97, p<$ .0001. Para evaluar la fuente de la interacción se realizó un ANOVA para cada filmina, hallándose que las del orden 6 , 7, 8, y 10 no mostraron diferencias significativas entre los grupos; en cambio en todas las demás los sujetos del GE las calificaron como más emocionales $(p<.002)$.

La fase de post-cambio muestra un efecto significativo en el factor Grupo, $F(1,41)=10.59, p<.002$, y en el factor Filminas, $F(9,369)=13.72, p<.00001$ y sin efecto en la interacción Grupo x Filminas $(p>.05)$. Los sujetos del GE valoraron las filminas como menos emocionales respecto del GC.

Estos resultados muestran que el tiempo de observación en este diseño no es una medida sensible para diferenciar el valor emocional de las filminas de alta o baja activación, ya que todos los grupos disminuyen el tiempo de observación a medida que trascurre el experimento, debido posiblemente a la habituación, fatiga o aprendizaje. La escala de valoración emocional, en cambio, muestra que durante la fase de precambio los sujetos del GE valoran las filminas como más emocionales respecto del GC. Sin embargo la valoración de algunas filminas no se diferencian entre los grupos, y ellas están más concentradas al final de la serie. Este efecto puede deberse o bien a un problema en la selección de las imágenes, o a un efecto de fatiga en la tarea, ya que los sujetos de ambos grupos tenían la misma secuencia. A pesar de ello, los resultados obtenidos durante la fase de post-cambio muestran un fuerte efecto de CSN, al invertirse la valoración emocional de las filminas: los sujetos del GE las consideran menos emotivas que las del GC.

Dado que las filminas se presentaron en forma casi consecutiva, ya que después que los sujetos las evaluaban aparecía una cruz en la pantalla de sólo 2 seg., este diseño no puede descartar que el contraste negativo observado sea debido a un mecanismo periférico, de "arrastre" (carry-over en inglés) o de contraste perceptual.

\section{Experimento 2}

El Experimento 2 tiene por objetivo replicar el efecto de CSN y resolver los problemas hallados en el experimento anterior, modificando parte del protocolo experimental. Primero, se redujo el número de imágenes a 5 en cada fase para evitar el posible efecto de fatiga o habituación; segundo, se descartaron algunas imágenes en función de los resultados obtenidos en el estudio anterior, específicamente aquellas en las que no se habían hallado diferencias significativas en la fase de pre-cambio entre el GC y el GE; tercero, la presen- tación de las filminas se realizó en forma aleatoria para evitar un efecto del orden de presentación, y cuarto, después que los sujetos respondían sobre la valoración emocional de las filminas con la escala Likert, se les presentaba una tarea distractora relativamente simple pero que requería concentración. La utilización de este tipo de tareas permite atenuar el pensamiento pasivo que podría estar favoreciendo el recuerdo de las fotografías anteriores y que los sujetos la comparen con la presente usando mecanismos de memoria sensorial (e.g., Cadavid, Beato y Fernández, 2012; Harris y Pashler, 2005).

\section{Método}

Participantes e instrumentos

Participaron 31 personas (14 hombres y 17 mujeres), entre 20 y 63 años de edad. Los instrumentos y situación experimental fueron iguales a los utilizados en el Experimento 1. El Apéndice 1 informa sobre las filminas que se usaron en este experimento.

\section{Procedimiento}

$\mathrm{El}$ procedimiento fue igual al anterior, con las siguientes excepciones:

1) Familiarización. Se eliminó la cruz que aparecía entre la secuencia de ensayos y se la reemplazó con un intervalo entre ensayos de $40 \mathrm{~s}$ en el que los sujetos debían resolver una serie de cálculos matemáticos de baja complejidad.

2) Fase de Pre-cambio. A los sujetos del GE $(n=16)$ se les presentaban, de forma aleatoria, una serie de cinco filminas de valencia de alta activación. A los sujetos del GC ( $n$ $=15$ ) se les presentaban 5 filminas de baja activación. El método de presentación fue el mismo que en la etapa de familiarización.

3) Fase de Post-cambio. Comenzaba a continuación de la resolución de los cálculos matemáticos luego de la filmina cinco. Se presentaron otra serie de cinco filminas de baja activación, siendo las mismas para ambos grupos.

Las variables dependientes y el análisis de datos fueron los mismos que los utilizados en el Experimento 1.

\section{Resultados y discusión}

Los análisis no mostraron diferencias significativas en función del sexo $(p>.05)$ por lo cual se realizó un ANOVA mixto con el factor intersujeto Grupo (experimental-control) y el factor intrasujeto Filminas, en las dos medidas y en cada fase.

Tiempo de observación: En ninguna de las fases se hallaron efectos significativos de los factores ni de su interacción $(p>$ $.05)$. 
Escala Likert. La Figura 2 muestra el promedio de la valoración de las filminas otorgadas por el GC y GE en función de la secuencia de las figuras. Se observa que en la fase de pre-cambio el GE valoró las filminas como más emocionales que el GC y en la fase de post-cambio su valoración se invierte, siendo menor que la puntuación del GC. Un ANOVA arrojó los siguientes resultados. En la fase de pre-cambio se halló un efecto significativo del Factor Grupo, $F(1,29)=$ $20.36, p<.0001$. El GE puntuó las filminas como más emocionales que el GC. Los demás factores no mostraron significación alguna, $p>.05$. Este resultado valida la selección de las filminas utilizadas. En la fase de post-cambio se halló un efecto significativo del Factor Grupo, $F(1,29)=7.74, p<$ .009. Los sujetos del GE invirtieron la valoración respecto de los del GC, puntuando las filminas significativamente por debajo del GC. No se halló efecto del factor Filminas ni de la interacción Grupo x Filminas, $p>.05$.

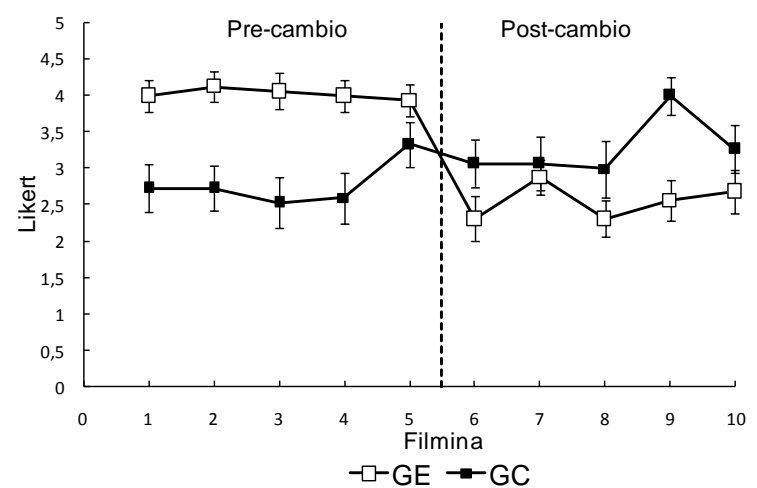

Figura 2. Experimento 2. Promedio ( $\pm E T M)$ de la evaluación emocional de las fotos del IAPS en función de las filminas y los grupos. GE: Grupo experimental; GC: Grupo control.

\section{Conclusiones}

Tanto en el Experimento 1 como en el Experimento 2 se mostró que la medida de tiempo de observación de las filminas no resultó sensible para medir el efecto de contraste negativo ni la diferencia de activación de las figuras. En un estudio previo se halló que los sujetos miraban más tiempo las imágenes muy placenteras y muy desagradables que las imágenes neutras de igual nivel de activación (SánchezNavarro et al., 2006). Este estudio sugiere por primera vez que el grado de activación no influye en el tiempo de observación de las filminas del IAPS. De todos modos esta afirmación se debe tomar con precaución porque nuestros resultados negativos pueden deberse a otros factores. Uno de ellos podría ser que los participantes hayan tomado como objetivo principal la evaluación de las filminas, y entonces optimizaron su rendimiento, como está sugerido en el Experimento 1, en el cual disminuyeron su tiempo de observación en función de la secuencia de presentación.

La valoración emocional de las filminas con la escala Likert pudo detectar un efecto de CSN en los sujetos experi- mentales. En ambos estudios, los participantes del GE durante la fase de pre-cambio juzgaron las filminas como más emocionales que los del GC, permitiendo validar su elección previa. En cambio, cuando se les presentaron las filminas de baja activación después de las altamente emocionales, realizaron una valoración por debajo de los participantes del GC, que siempre se expusieron a filminas de baja activación. Este efecto se observó en el Experimento 1 y se replicó en el Experimento 2 , cuando se interpuso la realización de una tarea distractora de $40 \mathrm{~s}$ entre cada ensayo. Este último resultado sugiere que se está ante la presencia de un efecto de origen central, producto de la violación de una expectativa, y no de un proceso periférico de contraste sensorial. Por otra parte, el Experimento 2 muestra que con sólo 5 presentaciones previas de imágenes de alta activación es suficiente para obtener un fuerte efecto de contraste negativo, ya que se produjo en las 5 figuras presentadas en la fase de post-cambio, sin notarse un acercamiento a la valoración que hicieron los sujetos del GC.

Este es el primer trabajo que revela la existencia de un efecto de CSN en la valoración emocional de imágenes. Desde una perspectiva teórica muestra que la influencia del aprendizaje sobre las reacciones ante imágenes se extiende a un fenómeno no estudiado, y por otra parte evidencia la existencia del efecto de CSN a imágenes con contenido emocional.

Estos experimentos indican que la valoración emocional de las imágenes se modula en función de las expectativas, pero no pueden evaluar si el efecto está asociado a reacciones emocionales. La mayoría de los estudios publicados indican que la valoración de imágenes varía en función de las emociones que provocan (ver Pace-Schott et al., 2011). Por ejemplo, Hamm et al. (1993) mostraron que los juicios acerca de las imágenes cambian después de un condicionamiento en el que se las apareaban con descargas eléctricas, y esa valoración correlacionaba a la vez con alteraciones en la respuesta galvánica de la piel, la tasa cardíaca y el reflejo de sobresalto. Bradley, Codispoti, Sabatinelli y Lang (2001) hallaron que el juicio de valor de figuras activantes del IAPS varía entre hombres y mujeres, juicio que correlaciona con la respuesta emocional medida por distintos parámetros fisiológicos. Finalmente Pahlavan y Lubart (2005) mostraron que la evaluación emocional de las figuras del IAPS está modulada en función de los estados emocionales específicos e inmediatos que experimentaban los sujetos que las observaban, relacionados o no con las figuras que los mismos experimentadores manipulaban. Todos estos antecedentes sugieren que la evaluación emocional que hacen las personas de las figuras está relacionada con sus estados emocionales. Teniendo en cuenta estos datos, la divergencia en el juicio de las imágenes que presentaron los sujetos del GE respecto de los del GC durante la fase de post-cambio podría estar asociada al estado emocional provocado, que se vincularían en este caso a un efecto de CSN. Para averiguarlo, las futuras investigaciones deberán tender a evaluar el estado emocional que provocan los cambios de imágenes con preguntas específicas rela- 
cionadas con el estado emocional que les provoca o con técnicas que registren la actividad neuronal o las respuestas autonómicas asociadas a reacciones emocionales, por ejemplo alteraciones en la tasa cardíaca, respuesta galvánica de la piel, etc.

\section{Referencias}

Amsel, A. (1992). Frustration theory. Cambridge, UK: Cambridge University Press. Appleton. Madrid: Alianza.

Bentosela, M., Jakovcevic, A., Elgier, A. M., Mustaca, A. E. y Papini, M. R. (2009). Incentive contrast in domestic dogs (Canis familiaris). Journal of Comparative Psychology, 123(3), 125-130.

Bradley, M. M., Codispoti, M., Sabatinelli, D. y Lang, P. J. (2001). Emotion and Motivation II: Sex Differences in Picture Processing. Emotion, 1(1), 300-319.

Bradley, M. M., Lang, P. J. y Cuthbert, B. N. (1993). Emotion, Novelty, and the Startle Reflex: Habituation in Humans. Behavioral Neuroscience, 107(6), 970-980.

Cadavid, S., Beato, M. S. y Fernández, A. (2012). Falso reconocimiento en listas DRM con tres palabras críticas: Asociación directa vs. Inversa. Psicológica, 33, 39-58.

Carretié, L., Ríos, M., De la Gándara, B. S., Tapia, M., Albert, J., LópezMartín, S. et al. (2009). The striatum beyond reward: caudate responds intensely to unpleasant pictures. Neuroscience, 164(4), 1615-1622.

Colegio de Psicólogos de Buenos Aires (Argentina). Código de ética. Recuperado http://www.proyectoetica.org/.../normativas.../Código\%20APBA).

Cuenya, L., Fosacheca, S., Mustaca, A. y Kamenetzky, G. (2011). Efecto del aislamiento en la adultez sobre el dolor y la frustración. Psicológica, 32, 49-63.

Cuenya, L., Sabariego, M., Donaire, R., Fernández-Teruel, A., Tobeña, A., Gómez, M. J. et al. (2012). The effect of Partial Reinforcement on Instrumental Successive Negative Contrast in inbred Roman High(RHA-I) and Low-(RLA-I) Avoidance Rats. Physiology y Behavior, 105(5), 1112-1116.

Cuthbert, B. N., Bradley, M. M. y Lang, P. J. (1996). Probing picture perception: activation and emotion. Psychophysiology, 33(2), 103-111.

Flaherty, C. F. (1996). Incentive relativity. Cambridge, UK: Cambridge University Press.

Flaherty, C. F., Becker, H. C. y Pohorecky, L. (1985). Correlation of corticosterone elevation and negative contrast varies as a function of postshift day. Animal Learning y Behavior, 13(3), 309-314.

Flaherty, C. F., Blitzer, R. y Collier, G. H. (1978). Open field behaviors elicited by reward reduction. American Journal of Psychology, 91(3), 429443.

Freidin, E., Cuello, M. I. y Kacelnik, A. (2009). Successive negative contrast in a bird: starlings' behaviour after unpredictable negative changes in food quality. Animal Behaviour, 77(4), 857-865

Gray, J. A. y McNaughton, N. (2000). The Neuropsychology of Anxiety: An Enquiry into the Functions of the Septo-Hippocampal System (2 ed.). (Oxford Psychology Series No. 33). Oxford: Oxford University Press.

Hamm, A. O., Greenwald, M. K., Bradley, M. M. y Lang, P. J. (1993). Emotional Learning, Hedonic Change, and the Startle Probe Journal of $A b$ normal Psychology, 102(3), 453-465.

Harris, C. H., y Pashler, H. (2005).Enhanced memory for negatively emotionally charged pictures without selective rumination. Emotion, 5(2), 191-199.

Kamenetzky, G. V., Cuenya, L., Elgier, A. M, López Seal, F., Fosacheca, S., Martin, L. et al. (2009). Respuestas de frustración en humanos. Terapia Psicológica, 27(2), 191-201.
Agradecimientos.- Este trabajo fue parcialmente financiado por el Consejo Nacional de Investigaciones Científicas y Técnicas (CONICET) y la Agencia Nacional de Promoción Científica y Tecnológica. Agradecemos al Dr. Rubén Muzio por otorgarnos las imágenes del IAPS y al Dr. Santiago Pellegrini por su activa colaboración en la realización de estudios preliminares sobre esta investigación. También agradecemos los comentarios de los revisores anónimos que permitieron mejorar el manuscrito.

Kraebel, K. S., Fable, J. y Gerhardstein, P. (2004). New methodology in in fant operant kicking procedures: computerized stimulus control and computerized measurement of kicking. Infant Behavior y Development, 27(1), 1-18.

Lang, P. J. y Bradley, M. M. (2010). Emotion and the motivational brain. Biological Psychology, 84(3), 437-450.

Lang, P. J., Bradley, M. M. y Cuthbert, B. N. (1999). International Affective Picture System: Instruction manual and affective ratings. Technical Report A-4, The Center for Research in Psychophysiology, University of Florida.

Marcos, J. M. y Redondo, J. (2004). Modulación del reflejo de parpadeo mediante condicionamiento con imágenes aversivas como estímulos incondicionados. Psicothema, 16(3), 391-396.

Mischel, W. y Masters, J. (1966). Effects of probability of reward attainment on responses to frustration. Journal of Personality and Social Psychology, 3 , 390-396.

Moeller, S. J., Maloney, T., Parvaz, M. A., Dunning, J. P., Alia-Klein, N., Woicik, P. A. et al. (2009). Enhanced Choice for Viewing Cocaine Pictures in Cocaine Addiction. Biological Psychiatry, 66(2), 169-176.

Mustaca, A. E., Bentosela, M. y Papini, M. R. (2000). Consummatory Successive Negative Contrast in Mice. Learning and Motivation, 31(3), 272282.

Neumann, R. y Lozo, L. (2012, January 16). Priming the activation of fear and disgust: Evidence for semantic processing. Emotion. Advanced online publication. doi: 10.1037/a0026500

Pace-Schott, E. F., Shepherd, E., Spencer, R. M., Marcello, M., Tucker, M., Propper, R. et al. (2011). Napping promotes inter-session habituation to emotional stimuli. Neurobiology of Learning and Memory, 95(1), 24-36.

Pahlavan, F. y Lubart, T. (2005). Negative affective states' effects on perception of affective pictures. En: Ellis, Ralph D., Newton, Natika. Con sciousness y emotion: Agency, conscious choice, and selective perception (pp. 57-80). Amsterdam, Netherlands: John Benjamins Publishing Company.

Papini, M. R., Wood, M., Daniel, A. M. y Norris, J. N. (2006). Reward Loss as Psychological Pain. International Journal of Psychology and Psychological Therapy, 6(2), 189-213.

Patrick, C. J., Bradley, M. M. y Lang, P. (1993). Emotion in the criminal psychopath: startle reflex modulation. Journal of Abnormal Psychology, 102(1), $82-92$.

Patrick, C. J. y Lavoro, S. A. (1997). Ratings of emotional response to pictorial stimuli: positive and negative affect dimensions. Motivation and Emotion, 21(4), 297-321.

Pellegrini, S. y Mustaca, A. E. (2000). Consummatory successive negative contrast with solid food. Learning y Motivation, 31(2), 200-209.

Sánchez-Navarro, J. P., José María Martínez-Selva, J. M. Román, F. y Torrente, G. (2006). The Effect of Content and Physical Properties of Affective Pictures on Emotional Responses. The Spanish Journal of Psychology, 9(2), 145-153.

Smith, J. C., Bradley, M. M. y Lang, P. J. (2005). State anxiety and affective physiology: effects of sustained exposure to affective pictures. Biological Psychology, 69(3), 247-260.

(Artículo recibido: 14-04-2011; revisado: 16-10-2012; aceptado: 16-10-2012) 


\section{Anexo. Consentimiento informado}

Consejo Nacional de Investigaciones Científicas y Técnicas (CONICET). Instituto de Investigaciones Médicas (IDIM). Psicología Experimental y Aplicada (PSEA)

Investigador a Cargo: Dr. Santiago Pellegrini

POR FAVOR, LEA ESTE DOCUMENTO EN DETALLE. FÍRMELO SÓLO SI ESTÁ DE ACUERDO EN PARTICIPAR Y COMPRENDE CLARAMENTE SUS DERECHOS. SU FIRMA ES UN REQUERIMIENTO NECESARIO PARA PARTICIPAR. SI DESEA UNA COPIA DE ESTE FORMULARIO DE CONSENTIMIENTO INFORMADO PUEDE PEDIRLO Y NOSOTROS SE LO DAREMOS. La política de nuestro departamento de psicología es que todos los participantes son voluntarios y usted tiene el derecho de abandonar en cualquier momento que lo desee, sin ningún perjuicio, si no está de acuerdo con continuar. Sus respuestas son confidenciales y secretas. La utilización de la información será de modo general, y nunca se identifica a los individuos participantes.

Si tiene dudas respecto de su participación en esta investigación puede contactar a: Dr. Santiago Pellegrini o Dra. Alba E. Mustaca. Tel: 4514-8701, interno 170.

Descripción del estudio: Este estudio consta de una sola sesión de aproximadamente 10 minutos, en la que se evalúan diversos tipos de medidas psicológicas. Para ello le pediremos que observe algunas imágenes en la pantalla de una computadora, en algunos casos con contenido sexual, y que responda una lista de preguntas simples.

Propósito del estudio: Estudiamos diferentes reacciones de las personas a imágenes y su relación con otros aspectos psicológicos. En términos generales, buscamos saber si la utilización de imágenes puede ser útil para estudiar los procesos psicológicos humanos y cómo reacciona la gente. Actualmente NO estamos interesados en estudiar a ninguna persona de manera individual o particular, sino grupos de personas en conjunto.

Posibles riesgos: Usted podría sentir que sus respuestas han sido poco satisfactorias. Tenga en cuenta que en la prueba no existen respuestas correctas o incorrectas. Sólo nos interesan sus respuestas tal como son.

Beneficios posibles: a) Una vez finalizada su participación podrá aprender diversas cosas del presente estudio. b) Estará ayudando al avance del conocimiento de la psicología.

Confidencialidad: Usted tendrá asignado un código de número. Su nombre no aparecerá en ninguno de nuestros archivos. Nadie podrá saber cuáles han sido sus respuestas particulares. Recuerde que no estamos interesados en conocer las respuestas de una persona en particular, sino las de grupos de personas, en general.

He leído y comprendido el presente formulario, y entiendo que puedo pedir una copia del mismo.

Fecha:

Firma del Participante

Firma de quien recibe el consentimiento Informado 
Apéndice. Código de las filminas utilizadas en los Experimentos 1 y 2 (IAPS).

\begin{tabular}{|c|c|c|c|c|}
\hline \multirow[b]{2}{*}{ Fase } & \multicolumn{4}{|l|}{ Experimento 1 } \\
\hline & Hombres GC & Hombre GE & Mujeres GC & Mujeres GE \\
\hline \multicolumn{5}{|c|}{ Familiarización } \\
\hline & 5779 & 5779 & 5891 & 5891 \\
\hline & 5830 & 5830 & 5660 & 5660 \\
\hline & 8185 & 8185 & 8180 & 8180 \\
\hline \multicolumn{5}{|c|}{ Pre-cambio } \\
\hline & 5760 & 8080 & 5870 & 8185 \\
\hline & 1610 & 4800 & 1450 & 8030 \\
\hline & 7325 & 4664 & 1910 & 8370 \\
\hline & 5891 & 5629 & 2370 & 5621 \\
\hline & 1620 & 4659 & 5030 & 8490 \\
\hline & 2340 & 8030 & 7545 & 4687 \\
\hline & 5870 & 8501 & 5010 & 8200 \\
\hline & 2331 & 4652 & 1610 & 8034 \\
\hline & 2170 & 5950 & 5780 & 8496 \\
\hline & 5831 & 4002 & 5779 & 4660 \\
\hline \multicolumn{5}{|c|}{ Post-cambio } \\
\hline & 5000 & 5000 & 5800 & 5020 \\
\hline & 5010 & 5010 & 5020 & 5720 \\
\hline & 2370 & 2370 & 5720 & 5000 \\
\hline & 7545 & 7545 & 5000 & 5750 \\
\hline & 2341 & 2341 & 5750 & 2320 \\
\hline & 2260 & 2260 & 2320 & 1603 \\
\hline & 8497 & 8497 & 1603 & 5220 \\
\hline & 2310 & 2310 & 5220 & 1604 \\
\hline & 2070 & 2070 & 1604 & 2560 \\
\hline & 4700 & 4700 & 2560 & 5800 \\
\hline & \multicolumn{4}{|l|}{ Experimento 2} \\
\hline & Hombres GC & Hombre GE & Mujeres GC & Mujeres GE \\
\hline \multicolumn{5}{|c|}{ Familiarización } \\
\hline & 5779 & 5779 & 5891 & 5891 \\
\hline & 5830 & 5830 & 5660 & 5660 \\
\hline & 8185 & 8185 & 8180 & 8180 \\
\hline \multicolumn{5}{|c|}{ Pre-cambio } \\
\hline & 5760 & 4800 & 5870 & 8185 \\
\hline & 1610 & 4664 & 1450 & 8030 \\
\hline & 7325 & 4659 & 1910 & 8370 \\
\hline & 5891 & 8030 & 5030 & 5621 \\
\hline & 1620 & 4652 & 7545 & 8490 \\
\hline \multicolumn{5}{|c|}{ Post-cambio } \\
\hline & 2340 & 2340 & 1610 & 1610 \\
\hline & 5870 & 5870 & 5780 & 5780 \\
\hline & 7545 & 7545 & 5720 & 5720 \\
\hline & 2341 & 2341 & 5750 & 5750 \\
\hline & 2260 & 2260 & 2320 & 2320 \\
\hline
\end{tabular}

